\title{
PENGARUH STRATEGI PEMBELAJARAN PHYSICAL SELF ASSESSMENT DENGAN MODEL JOYFUL LEARNING TERHADAP HASIL BELAJAR SISWA PADA MATERI STRUKTUR ATOM
}

\author{
Annisa Putri ${ }^{1)}$, Zona Octarya ${ }^{2)}$, Yuni Fatisa ${ }^{3)}$ \\ ${ }^{1), 2), 3)}$ Program Studi Pendidikan Kimia, Fakultas Tarbiyah dan Keguruan, UIN SUSKA Riau. \\ ${ }^{1)}$ Email: pannisa502@gmail.com \\ ${ }^{2)}$ Email: zona.octarya@uin-suska.ac.id \\ ${ }^{3)}$ Email: yunifatisa@uin-suska.ac.id
}

\begin{abstract}
This research was instigated by Chemistry subject at State Senior High School 1 Siak Hulu that was dominated by Lecturing method, and the low of student scores on Atomic Structure lesson in the Academic Year of 2016/2017. This research aimed at knowing the effect of Joyful Learning model with Recitation method using Physical Self-Assessment learning strategy toward student learning achievement on Atomic Structure lesson. Experimental method was used in this research with True experimental pretest posttest control group design. Purposive sampling technique was used in this research. The samples were the tenth-grade students of Natural Science 1 as the experimental group and the students of Natural Science 2 as the control group. The used instruments were learning achievement test that was supported by observation sheet and documentation. The research findings showed that $t_{\text {observed }}$ score 2.74 and $t_{\text {table }}$ was 2.00 . It showed that $t_{\text {observed }}$ was higher than $t_{\text {table }}$, there was an effect on learning achievement, and the effect was $11.5 \%$. So, it could be concluded that there was an effect of Joyful Learning model with Recitation method using Physical Self-Assessment learning strategy at State Senior High School 1 Siak.
\end{abstract}

Keywords: Joyful Learning Model, Recitation Method, Physical Self-Assessment Learning Strategy, Learning Achievement, Atomic Structure

\section{PENDAHULUAN}

Pendidikan merupakan suatu hal yang sangat penting bagi kehidupan kita. Pentingnya pendidikan menyebabkan perlu adanya peningkatan mutu dalam pendidikan yang dilakukan secara menyeluruh mencakup pengembangan dimensi manusia Indonesia seutuhnya yakni aspek-aspek moral, akhlak, budi pekerti, perilaku, pengetahuan, kesehatan, keterampilan, dan seni.[1]. Pendidikan juga berperan penting bagi perkembangan peradaban bangsa. Bangsa yang maju adalah bangsa yang berkualitas. Guna menghasilkan sumber daya manusia yang berkualitas perlu adanya sistem pendidikan yang berkualitas pula. Sebagaimana tertuang dalam pasal 1 Undang-undang Nomor 20 tahun 2003 tentang Sistem Pendidikan Nasional, tujuan pendidikan adalah berkembangnya potensi peserta didik agar menjadi manusia yang beriman dan bertakwa kepada Tuhan Yang Maha Esa, berakhlak mulia, sehat, berilmu, cakap, kreatif, mandiri, dan menjadi warga negara yang demokratis serta bertanggung jawab. Ketercapaian tujuan pendidikan nasional bergantung pada keberhasilan proses belajar mengajar antara guru dan siswa. Peran guru dalam hal ini adalah membelajarkan sedangkan peran siswa adalah belajar.

Pembelajaran yang baik adalah pembelajaran yang aktif, kreatif, inovatif dan menyenangkan. Aktif dimaksudkan bahwa proses pembelajaran guru harus menciptakan suasana sedemikian rupa sehingga siswa bertanya, mempertanyakan dan mengemukakakan gagasan. Kreatif artinya memiliki daya cipta, dan memiliki kemampuan berkreasi. Pembelajaran yang menyenangkan akan selalu menggugah rasa ingin tahu siswa terhadap sesuatu, dan diharapkan dapat menciptakan suasana belajar yang menyenangkan, bermakna, dinamis dan kreatif.

Penyebab rendahnya hasil belajar siswa adalah siswa merasa pembelajaran kimia itu sulit, aktivitas siswa masih mendengarkan guru, mencatat pelajaran, dan mengerjakan soal di depan kelas, serta dikarenakan kimia memiliki perbendaharaan kata yang khusus, dimana 
mempelajari kimia seperti mempelajari bahasa yang baru. Selain itu, dalam pembelajaran kimia terdapat pemahaman konsep, perhitungan dan hafalan.

Berdasarkan wawancara dengan Ibu Handalia, S.Pd., pada tanggal 10 Desember 2017 di SMA Negeri 1 Siak Hulu diperoleh informasi bahwa guru kimia masih menggunakan cara konvensional dalam mengajar. Guru lebih terfokus pada ketercapaian target materi pelajaran dan bukan pada keterlibatan siswa dalam pembelajaran, padahal seharusnya pelajaran kimia melibatkan siswa secara aktif, menyelesaikan suatu masalah, dan memilih metode yang sesuai dengan karakter mata pelajaran.

Berdasarkan fakta di lapangan, diketahui bahwa ternyata masih banyak siswa kelas $\mathrm{X}$ SMA Negeri 1 Siak Hulu yang mengalami kesulitan dalam memahami materi kimia serta siswa merasa dalam pemberian tugas mereka terbebani dengan cara guru yang masih konvensional. Berbagai cara bisa dilakukan oleh guru, salah satu cara untuk mewujudkan suasana pembelajaran yang menarik dan penuh inovasi adalah dengan cara menerapkan model pembelajaran yang memberi kesempatan kepada siswa untuk berinteraksi, saling bertukar pikiran, siswa aktif dalam pembelajaran, pembelajaran dituntut untuk melakukan diskusi antar siswa, bekerja sama dalam kelompok serta melibatkan dalam membuat kesimpulan. Secara teoritis untuk mengatasi permasalahan tersebut diantaranya dengan cara menerapkan model pembelajaran kooperatif[2].

Salah satu alternatif model pembelajaran yang diharapkan dapat menciptakan kondisi belajar yang menyenangkan, tanpa beban, dan aktif serta melibatkan siswa adalah Joyful Learning atau pembelajaran menyenangkan. Pembelajaran Joyful Learning merupakan salah satu model pembelajaran yang bisa diterapkan di beberapa bidang mata pelajaran, termasuk Kimia. Pembelajaran ini memiliki ciri menyenangkan, melibatkan siswa, dan menuntut siswa untuk aktif. Di Indonesia, pembelajaran Joyful Learning lebih dikenal sebagai model PAKEM (Pembelajaran Aktif, Kreatif, Efektif, dan Menyenangkan)[3].
Pada dasarnya materi pembelajaran akan mudah diterima siswa apabila didukung oleh metode yang tepat yang dapat mendorong siswa untuk lebih aktif. Salah satu metode belajar yang dapat mengembangkan keaktifan siswa adalah metode pemberian tugas. Metode pemberian tugas merupakan metode yang berorientasi pada filosofi konstruktivistik[4].

Metode pemberian tugas adalah cara penyajian pelajaran dengan menugaskan pelajar-pelajar mempelajari sesuatu yang kemudian harus dipertanggung jawabkan dengan diskusi. Metode pemberian tugas dapat diberikan pada saat proses pembelajaran salah satunya adalah pada saat penerapan pembelajaran menggunakan strategi pembelajaran Physical Self Assessment.

Strategi Physical Self Assessment adalah mempersiapkan diri dalam kelompok serta sejauh mana tingkat pemahaman siswa atas materi yang diberikan oleh guru dan dapat memberikan motivasi kepada siswa untuk mempelajari dan menggali kembali sumbersumber yang berkaitan dengan materi, sebagai sarana dalam mengerjakan tugas-tugas yang diberikan guru[5].

Adapun beberapa penelitian pendukung seperti (a) penelitian yang telah dilakukan oleh Pramesthi, Nugroho, dan Selfi tentang penerapan pendekatan joyful learning dengan metode discovery. Dalam penelitian ini pembelajaran yang menerapakan model joyful learnig meningkatkan rasa ingin tahu siswa serta prestasi belajar[6]. (b) penelitian lain diteliti oleh Permatasari, Mulyani efektivitas penggunaan model joyful learning dengan metode pemberian tugas terhadap prestasi belajar siswa pada materi koloid siswa kelas XI IPA didapatkan hasil bahwa dengan metode pemberian tugas ini mampu membuat siswa lebih aktif. (c) dan peneliti lain oleh Hamid, pengaruh strategi pembelajaran phsical self sssessment terhadap Hasil Belajar Siswa didapatkan hasil bahwa peningkatan terhadap hasil belajar siswa serta keaktifan siswa dalam belajar[7].

\section{METODE PENELITIAN}

Penelitian ini dilaksanakan pada bulan Penelitian dilaksanakan pada bulan Juli- 
September tahun ajaran 2018/2019, tempat penelitian dilaksanakan di SMA Negeri 1 Siak Hulu. Populasi dalam penelitian ini adalah seluruh siswa kelas X SMA Negeri 1 Siak Hulu tahun ajaran 2018/2019. Dalam penelitian ini sampel diambil hanya 2 kelas. Satu kelas untuk kelas kontrol dan satu kelas untuk kelas eksperimen. Pengambilan sampel ini menggunakan teknik purposive sample. Teknik sampling ini dilakukan dengan cara mengambil subjek bukan berdasarkan atas strata, random atau daerah tetapi didasarkan atas tujuan tertentu..

Penelitian ini adalah penelitian True Experiment yang dilakukan terhadap dua kelas, yaitu kelas kontrol dan kelas eksperimen. Dimana kelas kontrol menggunakan metode pembelajaran Joyful Learning dengan metode pemberian tugas, sedangkan kelas eksperimen diberi menggunakan kelas eksperimen yang dilaksanakan menggunakan metode pembelajaran Joyful Learning dengan metode pemberian tugas menggunakan strategi pembelajaran physical self assessment, dengan desain penelitian pretest-posttest control group design.

Tabel 1. pretest-posttest control group design

\begin{tabular}{lccc}
\hline Kelompok & $\begin{array}{c}\text { Pre- } \\
\text { test }\end{array}$ & Perlakuan & $\begin{array}{l}\text { Post- } \\
\text { test }\end{array}$ \\
\hline Kontrol & $\mathrm{T}_{1}$ & $\mathrm{X}_{\mathrm{a}}$ & $\mathrm{T}_{2}$ \\
\hline Eksperimen & $\mathrm{T}_{1}$ & $\mathrm{X}_{\mathrm{b}}$ & $\mathrm{T}_{2}$ \\
\hline
\end{tabular}

$\mathrm{T}_{1} \quad$ : Pre-test dikelas kontrol dan kelas eksperimen

$\mathrm{X}_{\mathrm{a}}$ : Perlakuan yang diberikan dikelas kontrol

$\mathrm{X}_{\mathrm{b}} \quad$ : Perlakuan yang diberikan dikelas eksperimen

$\mathrm{T}_{2} \quad$ : Post-test dikelas kontrol dan kelas eksperimen

Metode pengumpulan data yang digunakan pada penelitian ini adalah metode tes, observasi, dan dokumentasi. Tes adalah alat atau prosedur yang dipergunakan dalam rangka pengukuran dan penilaian[8]. Dalam penelitian ini digunakan pretest untuk melihat kemampuan awal siswa sebelum diberikannya perlakuan dan posttest untuk melihat hasilnya ketika sudah diberikan perlakuan.
Metode observasi adalah cara menghimpun bahan-bahan data yang dilakukan dengan mengadakan pengamatan dan pencatatan secara sistematis terhadap fenomena-fenomena yang sedang dijadikan sasaran penelitian. Observasi dalam penelitian ini dimaksudkan untuk melihat secara langsung proses pembelajaran yang dilakukan, termasuk sistem dan metode pembelajaran yang digunakan yang berkaitan dengan kemampuan kognitif siswa pada saat penelitian berlangsung. Selanjutnya metode dokumentasi ialah pengambilan data yang diperoleh melalui dokumen-dokumen. Pada teknik ini, peneliti dimungkinkan memperoleh informasi dari bermacam-macam sumber tertulis atau dokumen yang ada pada responden atau tempat, dimana responden bertempat tinggal atau melakukan kegiatan sehari-harinya.

Data yang didapat dari dokumentasi ini adalah, nilai siswa, proses pembelajaran yang mana menerapkan strategi pembelajaran physical self assessment dengan model joyful learning didalam kelas, foto-foto saat siswa mengerjakan tes awal dan akhir.

Instrumen yang digunakan dalam penelitian ini adalah soal pretest dan posttest. Instrumen soal tersebut harus divaliditas isi dan empiris. Validitas isi adalah validitas yang diperoleh setelah dilakukan penganalisisan, penelusuran atau pengujian terhadap isi yang terkandung dalam instrumen tersebut. Validitas isi instrumen dilakukan oleh Dosen Pembimbing dan Guru Kimia SMA Negeri 1 Siak Hulu. Setelah instrumen itu divaliditas isi, kemudian direvisi dan divaliditas seacara empiris. Validitas empiris adalah ketepatan mengukur yang didasarkan pada hasil yang bersifat empiris. Maksudnya yaitu validitas yang bersumber atau diperoleh atas dasar pengamatan lapangan.

Validitas empiris dilakukan dengan cara menguji cobakan soal tersebut pada siswa yang telah mempelajari materi struktur atom. Validitas empiris dilakukan di Kelas XI IPA 1, dengan jumlah sampel sebanyak 32 siswa. Soal yang diuji cobakan sebanyak 30 soal. Validitas empiris terdiri dari empat bagian yaitu validitas item, reliabilitas tes, daya pembeda soal, dan tingkat kesukaran. Berdasarkan uji validitas 
empiris maka untuk soal pretest dan posttest yang dapat digunakan dalam penelitian terdiri dari 20 soal yaitu nomor $1,2,3,4,6,7,8,11$, 12, 13, 15,16, 18, 20, 21, 22, 23, 24, 26, 27.

Untuk teknik pengolahan data yang digunakan dalam penelitian ini adalah uji prasyarat yaitu uji normalitas dan uji homogenitas. Setelah diketahui apakah datanya normal dan homogen selanjutnya dilakukan uji hipotesis menggunakan uji $\mathrm{t}$ test melalui pengolahan data menggunakan SPSS versi 22 . Hipotesis yang diujikan dalam penelitian ini yaitu:

$\mathrm{H}_{\mathrm{a}} \quad$ : Adanya pengaruh strategi pembelajaran
physical self assessment dengan model
joyful learning terhadap hasil belajar
siswa pada materi struktur atom
$\mathrm{H}_{\mathrm{o}} \quad$ : Tidak adanya pengaruh strategi
pembelajaran physical self assessment
dengan model joyful learning terhadap
hasil belajar siswa pada materi struktur
atom

\section{HASIL DAN PEMBAHASAN}

Peneliti melakukan penelitian pada 2 Kelas IPA, yaitu X IPA1 kelas eksperimen dan X IPA 2 kelas kontrol. Jumlah sampel yang digunakan sama yaitu 30 siswa/kelas. Uji hipotesis menggunakan data nilai pretest dan posttest. Sebelum dilakukan uji hipotesis, dilakukan uji prasyarat yaitu uji normalitas dan homogenitas.

Uji normalitas dilakukan menggunakan data hasil belajar siswa pada materi sebelumnya yaitu materi hakikat ilmu kimia. Uji normalitas yang digunakan yaitu Chi Kuadrat $\left(\mathrm{X}_{2}\right)$. Data dikatakan berdistribusi normal apabila $X_{\text {hitung }}^{2} \leq X_{\text {tabel }}^{2}$, jika kedua data mempunyai sebaran yang normal, maka langkah selanjutnya dilakukan uji homogenitas agar uji tes " $t$ " dapat dilanjutkan. Data uji normalitas kelas eksperimen yaitu $0,065<11,070$, maka data yang tersebar pada kelas ekperimen normal. Data uji normalitas kelas kontrol yaitu $0,032<$ 15,507 , maka data yang tersebar pada kelas kontrol normal.

Kemudian uji homogenitas dilakukan untuk mengetahui apakah data memiliki varians yang sama atau homogen. Uji homogenitas ini dilakukan sebelum peneliti memberikan pretest. Soal yang digunakan pada uji homogenitas ini yaitu soal objektif 10 soal materi hakikat ilmu kimia. Apabila $F_{\text {hitung }}<\mathrm{F}_{\text {tabel }}$ dengan taraf signifikan 0,05 maka data dikatakan mempunyai varians yang sama atau homogen. Setelah uji homogenitas dilakukan, maka diperoleh hasil $F_{\text {hitung }}$ sebesar 1,80 dan $F_{\text {tabel }}$ 1,85. Hasil tersebut menunjukkan bahwa data sudah memiliki varians yang sama atau homogen.

Setelah diketahui data dalam penelitian normal dan homogen selanjutnya dilakukan uji hipotesis. Berdasarkan hasil pretest yang telah dilakukan, kelas eksperimen mempunyai ratarata nilai $27,83 \%$ dan kelas kontrol yaitu $28,67 \%$. Hal tersebut menunjukkan bahwa nilai pretest kelas kontrol lebih tinggi dibandingkan kelas eksperimen. Jika dilihat dari hasil posttest, nilai rata-rata posttest kelas eksperimen yaitu $74,83 \%$ dan kelas kontrol yaitu $64,33 \%$. Hasil tersebut menunjukkan bahwa terjadinya peningkatan rata-rata hasil belajar siswa. Pada kelas eksperimen terjadi peningkatan hasil belajar siswa sebesar $47 \%$ dan pada kelas kontrol sebesar 35,66\%. Peningkatan hasil belajar siswa pada kelas eksperimen lebih besar dibandingkan kelas kontrol.

Hasil uji signifikansi menggunakan paired samples t-test pada kelas eksperimen dan kelas kontrol yaitu $0,00<0,05$, hal tersebut menunjukkan bahwa pembelajaran pada kelas eksperimen maupun kelas kontrol memberikan dampak positif dan signifikan dalam meningkatkan hasil belajar siswa pada materi struktur atom. Tetapi, dari hasil posttest kedua kelas tersebut menunjukkan bahwa peningkatan nilai hasil belajar siswa kelas eksperimen lebih tinggi dibandingkan kelas kontrol. Selanjutnya dilakukan uji menggunakan rumus t-test dan diperoleh nilai $t_{\text {hitung }}=2,74$ dan $t_{\text {tabel }}=2,00$, yang menunjukkan $t_{\text {hitung }}>t_{\text {tabel. }}$. Dengan demikian, $\mathrm{H}_{0}$ ditolak dan $\mathrm{H}_{\mathrm{a}}$ yang diterima, yaitu adanya pengaruh model pembelajaran joyful learning dengan metode pemberian tugas menggunakan strategi pembelajaran physical self assessment terhadap hasil belajar siswa pada materi struktur atom di SMA Negeri 1 Siak Hulu. Hasil analisis Kp menunjukan bahwa besarnya koefisien pengaruh hasil belajar siswa kelas eksperimen dan kelas 
kontrol pada materi struktur atom adalah 11,5 $\%$.

Kategori kemampuan kognitif dapat digunakan istilah daya serap. Peneliti mengkategorikan kemampuan kognitif untuk melihat daya serap pada kelas eksperimen yang menggunakan strategi pembelajaran physical self assessment dan kelas kontrol tidak

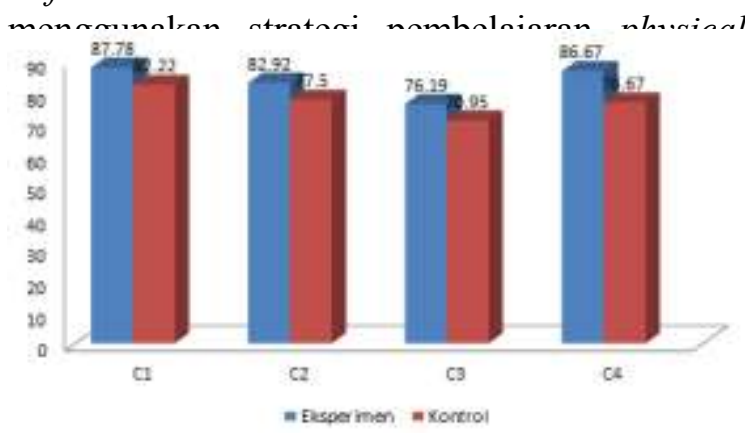

\section{Gambar 1. Kategori Kemampuan Kognitif}

Dari Gambar 1 diatas menunjukkan bahwa daya serap pada kelas eksperimen lebih tinggi dibandingkan kelas kontrol. Hal tersebut menunjukkan bahwa penerapan strategi pembelajaran physical self assessment memberikan dampak positif terhadap kemampuan siswa dalam menyerap materi yang disajikan oleh peneliti dalam proses pembelajaran kimia.

Hal ini relevan dengan penelitian sebelumnya yang telah dilakukan oleh Rizza dkk, yang menyatakan bahwa terdapat pengaruh pembelajaran joyful learning terhadap prestasi belajar siswa ranah kognitif, tetapi tidak terdapat pengaruh model pembelajaran terhadap prestasi belajar ranah afektif dan psikomotor[9].

Dengan adanya pembelajaran menggunakan strategi physical self assessment ini, siswa lebih antusias dan aktif saat pembelajaran berlangsung. Sesuai dengan penelitan yang dilakukan Putri dkk, yang menyatakan bahwa pengaruh strategi pembelajaran phsical self assessment berbasis joyful learning menunjukkan bahwa hasil belajar pada kelas dengan strategi pembelajaran phsical self assessment berbasis joyful learning lebih baik dibandingkan pembelajaran konvensional dan siswa memberikn respon positif terhadap penerapan model phsical self assessment. Selain itu strategi pembelajaran phsical self assessment berbasis joyful learning merupakan strategi untuk menjadikan belajar tidak terlupakan sekaligus dapat mengevaluasi kemajuan tingkat pemahaman mereka terkait dengan materi yang diajarkan maka joyful learning lebih baik dibandingkan pembelajaran konvensional dan siswa memberikan respon positif.

Dari hasil penelitian dapat disimpulkan bahwa strategi phsical self assessment dapat berpengaruh terhadap hasil belajar siswa pada materi struktur atom. Sebagaimana yang dikemukakan oleh Miterianifa bahwa strategi pembelajaran merupakan suatu kegiatan pembelajaran yang harus dikerjakan guru dan siswa agar tujuan pembelajaran dapat dicapai secara efektif dan efisien[10].

\section{KESIMPULAN}

Berdasarkan hasil penelitian yang dilakukan dapat disimpulkan bahwa ada pengaruh model joyful learning dengan metode pemberian tugas menggunakan strategi pembelajaran physical self assessment terhadap hasil belajar siswa pada materi struktur atom, hal itu dibuktikan dari hasil uji hipotesis, dengan $t_{\text {hitung }}>t_{\text {tabel }}$ yaitu 2,74 $>2,00$ besarnya koefisein pengaruh hasil belajar siswa adalah $11,5 \%$.

\section{REFERENSI}

[1] Aprilia Intan Permatasari, Bakti Mulyani, Nanik Dwi Nurhayati, "Efektivitas Penggunaan Model Joyful Learning dengan Metode Pemberian Tugas terhadap Prestasi Belajar Siswa pada Materi Koloid Siswa Kelas XI IPA SMA Negeri 1 Simo Tahun Pelajaran 2012/2013", Jurnal Pendidikan Kimia (JPK) Program Studi Pendidikan Kimia Universitas Sebelas Maret, Vol. 3 No. 1, hal. 117, 2014.

[2] Fitria Elisandra, Alimufi Arief, "Penerapan Model Pembelajaran Kooperatif Tipe Two Stay Two Stray 
dengan Media Poster untuk

Meningkatkan Hasil Belajar Siswa pada

Materi Pemanasan Global", Jurnal Inovasi Pendidikan Fisika (JIPF), Vol. 06 No. 03, hal. 149, 2017.

[3] Muhammad Rizza Umami, Suryadi Budi Utomo, dan Ashadi, "Pengaruh Media Infografis dan Poster pada Pembelajaran Joyful Learning terhadap Prestasi Belajar Siswa Ditinjau dari Kemampuan Logika pada Materi Pokok Kesetimbangan Kimia Kelas XI IPA Semester Gasal SMA Negeri Gondangrejo Tahun Pelajaran 2015/2016", Jurnal Pendidikan Kimia (JPK), Vol. 5 No. 3, hal. 10, 2016.

[4] Aprilia Intan Permatasari, Bakti Mulyani, Nanik Dwi Nurhayati, "Efektivitas Penggunaan Model Joyful Learning dengan Metode Pemberian Tugas terhadap Prestasi Belajar Siswa pada Materi Koloid Siswa Kelas XI IPA SMA Negeri 1 Simo Tahun Pelajaran 2012/2013", Jurnal Pendidikan Kimia (JPK), Vol. 3 No. 1, hal. 117, 2014.

[5] htpp://info189. Blogspot.com/ 2012/ 09/ physical self assesment dan modeling. html, diakses tgl 12 April 2018.

[6] Hilda Nita Pramesyhi, Agung Nugroho Catur, dan Elfi Susanti, "Penerapan Pendekatan Joyful Learning dengan Metode Guided untuk Meningkatkan Rasa Ingin Tahu dan Prestasi Belajar pada Materi Hidrokarbon Siswa Kelas X SMA Negeri 1 Ngemplak Boyolali tahun ajaran 2013/2014", Jurnal Pendidikan Kimia (JPK), Vol. 4 No. 1. hal. 210, 2015.

[7] Putri Dessy Primia Khusnul Khotimah dan Abdul Hamid, "Pengaruh Strategi Pembelajaran Phsical Self Assessment Berbasis Joyful Learning terhadap Hasil Belajar Siswa Kelas XI IPA SMA Negeri 5 Banjarmasin pada Materi Larutan Penyangga", Jurnal pendidikan kimia FKIP, Univeritas Lambung Mangkurat, Banjarmasin Vol. 6 No. 2, hal. 79. 2015.

[8] Anas Sudijono, Pengantar Evaluasi Pendidikan, (Jakarta: Raja Grafindo Prasada, 2009), Hal. 66.
[9] Muhammad Rizza Umami, Suryadi Budi Utomo, dan Ashadi, "Pengaruh Media Infografis dan Poster pada Pembelajaran Joyful Learning terhadap Prestasi Belajar Siswa Ditinjau dari Kemampuan Logika pada Materi Pokok Kesetimbangan Kimia Kelas XI IPA Semester Gasal SMA Negeri Gondangrejo Tahun Pelajaran 2015/2016", Jurnal Pendidikan Kimia (JPK), Vol. 5 No. 3, hal. 10, 2016.

[10] Putri Dessy Primia Khusnul Khotimah dan Abdul Hamid, "Pengaruh Strategi Pembelajaran Phsical Self Assessment Berbasis Joyful Learning terhadap Hasil Belajar Siswa Kelas XI IPA SMA Negeri 5 Banjarmasin pada Materi Larutan Penyangga", Jurnal pendidikan kimia FKIP, Univeritas Lambung Mangkurat, Banjarmasin Vol. 6 No. 2, hal. 79. 2015. 